\title{
Respostas morfológicas em Guibourtia hymenifolia (Moric.) J. Leonard (Fabaceae) e Genipa americana L. (Rubiaceae), submetidas ao estresse por deficiência nutricional e alagamento do substrato
}

\author{
ETENALDO F. SANTIAGO ${ }^{1,3}$ e ADELITA A.S. PAOLI ${ }^{2}$
}

(recebido: 15 de setembro de 2005; aceito: 8 de fevereiro de 2007 )

\begin{abstract}
Morphological responses in Guibourtia hymenifolia (Moric.) J. Leonard (Fabaceae) and Genipa americana L. (Rubiaceae) to nutrient deficit and flooding stress). The plastic responses of seedlings and young plants of two Brazilian native trees were studied. In G. hymenifolia no important morphological changes were found, except for starch reserve content that was lower in the lots in nutrient poor, drained soils (CCD), and nutrient poor, flooded soils (ALD). In Genipa americana the rich, drained soil group $(\mathrm{CCN})$ developed adventitious roots with evident aerenchyma, these roots were more frequent in the rich flooded soil (ALN) lots. In this group we also detected lysogenic aerenchyma formation and lenticular hypertrophy in the stem. The diversity of responses to flooding and the wide distribution of Genipa americana along seasonal flooded areas, as the Pantanal in Miranda, MS, suggests a complex interaction between morphological and physiological adaptative characters, where the genetic potential play an important role.
\end{abstract}

Key words - adventitious rooting, aerenchyma, biomass, flooding stress

RESUMO - (Respostas morfológicas em Guibourtia hymenifolia (Moric.) J. Leonard (Fabaceae) e Genipa americana L. (Rubiaceae), submetidas ao estresse por deficiência nutricional e alagamento do substrato). Foram estudadas as respostas plásticas em duas espécies nativas. Em G. hymenifolia, não foram verificadas modificações morfológicas significativas, exceto quanto ao conteúdo de amido de reserva, que foram menores nos lotes capacidade de campo desnutrido (CCD) e alagamento desnutrido (ALD). Em Genipa americana os indivíduos do lote (CCN - capacidade de campo nutrido) exibiram raízes adventícias com aerênquima distinto, estas raizes foram mais frequentes nas plantas do lote controle submetidas ao alagamento (ALN - alagado nutrido). Nesta espécie, nos lotes ALN, verificou-se o surgimento de aerênquima lisógeno no caule, além da hipertrofia lenticelar. A diversidade de respostas às condições de alagamento, aliadas à uma larga ocorrência de populações de Genipa americana em áreas sazonalmente inundadas, como por exemplo no Pantanal de Miranda-MS, sugerem um complexo de interações entre caractes adaptativos morfológicos e fisiológicos, sendo o potencial gênico fundamental neste tipo de resposta.

Palavras-chave - aerênquima, biomassa, estresse, raíz adventícia

\section{Introdução}

Diante dos atuais esforços na implementação de projetos de reposição de cobertura vegetal, sobretudo em ambientes frágeis como aqueles associados a recursos hídricos, parece óbvia a importância dos estudos que envolvam as respostas de plântulas de espécies nativas às condições de alagamento do substrato, uma vez que, nestes ambientes, são comuns as variações no estado hídrico dos solos, com modificações severas nas concentrações de oxigênio disponível para as raízes,

\footnotetext{
1. Universidade Estadual de Mato Grosso do Sul, Cidade Universitária, Laboratório de Ecologia GASLAB, Caixa Postal 351, 79804-970 Dourados, MS, Brasil.

2. Universidade Estadual Paulista, Instituto de Biociências, Departamento de Botânica, Caixa Postal 199, 13506-900 Rio Claro, SP, Brasil.

3. Autor para correspondência: felipe@uems.br
}

requerendo das plantas respostas rápidas às novas condições impostas.

Respostas morfológicas como o desenvolvimento de aerênquima, corredores de ar ou espaços aéreos descontínuos, raízes adventícias ou com crescimento diageotrópico e o aumento em superfície (Wample \& Reid 1979, Drew et al. 1981, Joly 1996, Scatena \& Meneses 1996, Santiago \& Paoli 2003), constituem-se em respostas expressas por plantas submetidas à hipóxia ou anoxia.

O desenvolvimento do aerênquima em plantas surge pelo afastamento (aerênquima esquisógeno) entre células na região da lamela média, formando grandes espaços intercelulares, como também é resultado da hidrólise da parede celular, e eventual lise celular (aerênquima lisógeno), promovida por etileno endógeno (Cutter 1978, Drew et al. 1981, He et al. 1996). Dantas et al. (2001) estudando plântulas de milho submetidas à hipóxia, destacaram a atividade da celulase na formação do aerêquima, bem como a inibição da formação destas 
estruturas pelo fornecimento exógeno de cálcio. He et al. (1999) estudando quatro espécies de ranunculáceas verificaram que Ranunculus repens L., a mais resistente ao alagamento, foi a que apresentou maior desenvolvimento do aerênquima.

Lenssen et al. (2004) estudando diferentes genótipos de Ranunculus reptans L. provenientes de ambientes de solos úmidos e ambientes de solos bem drenados, verificaram que, de maneira contrária ao esperado, genótipos provenientes de terra firme tiveram maior proporção de aerênquima em suas raízes comparada com as de micro-habitat de áreas úmidas, verificaram ainda que a eficiência no uso de carboidratos foi alta em todos os genótipos.

O estado nutricional das plantas submetidas ao alagamento também pode influenciar na expressão de respostas como a formação de aerênquima. He et al. (1992) verificaram que a deficiência temporária de nitrogênio e fósforo em plantas de milho alagada, aumenta a sensibilidade de tecidos da raíz ao etileno exógeno promovendo a lise celular e formação de aerênquima. Já Santiago \& Paoli (2003) estudando as respostas de Adelia membranifolia (Müll. Arg.) Pax \& K. Hoffm e Peltophorum dubium (Spreng.) Taub., submetidas ao alagamento, verificaram que o estado nutricional das plântulas influencia a expressão de caracteres mofológicos como a formação de aerênquima e raízes adventícias, sendo esta resposta mais efetiva nas plantas nutridas.

Funcionalmente as raízes adventícias substituem as raízes ocasionalmente mortas durante o alagamento (Vartapetian \& Jackson 1997) promovem o retorno ao metabolismo aeróbio do sistema radicial impedindo a formação de compostos tóxicos por vias fermentativas e auto envenenamento (Janiesch 1991, Lobo \& Joly 1995, Vartapetian \& Jackson 1997).

Reid \& Bradford (1984) abordando as causas do enraizamento adventício discutiram o possível papel do etileno e das auxinas na determinação destas respostas, admitindo um possível controle por complexos de fatores hormonais e nutricionais.

Do ponto de vista anatômico, as raízes adventícias diferem internamente das demais raízes por apresentarem uma maior proporção do córtex, redução do sistema de condução além de amplos espaços intercelulares e desenvolvimento de aerênquima.

Este trabalho objetivou investigar e discutir as respostas morfológicas e de biomassa vegetal, verificadas em plântulas e plantas jovens de duas espécies nativas submetidas ao estresse por deficiência nutricional e alagamento do substrato: Guibourtia hymenifolia (Moric.) J. Leonard, espécie arbórea, com características de secundária tardia a climáxica, com ocorrência em solos calcáreos e bem drenados nas formações semideciduais do Mato Grosso do Sul e Genipa americana L., arbórea, secundária, de ampla distribuição. Estas informações são importantes para ampliar o conhecimento acerca da biologia das espécies bem como servir de subsídio às propostas de utilização das mesmas em projetos de reposição de cobertura vegetal nativa.

\section{Material e métodos}

Sementes de Guibourtia hymenifolia, provenientes de coletas realizadas em trechos de floresta ciliar no Rio da Prata, no Município de Jardim, MS, Brasil (21 ${ }^{\circ} 24^{\prime}$ S e $56^{\circ} 22^{\prime}$ W), e sementes de Genipa americana, provenientes de indivíduos existentes no campus da UNESP Rio Claro, SP, foram submetidas a secagem prévia e armazenadas sob refrigeração em frascos de vidro.

Os aspectos morfo-anatômicos e de desenvolvimento foram avaliados em plântulas com cerca de 30 dias de emergência e plantas jovens com cerca de três a seis meses de desenvolvimento. Em G. hymenifolia, induziu-se a germinação em sementes escarificadas com $\mathrm{H}_{2} \mathrm{SO}_{4}$ por 15 minutos. Nenhum tratamento pré-germinativo foi realizado nas sementes de G. americana. As plântulas foram obtidas por semeadura direta em tubetes de polietileno contendo substrato agrícola Plantimax em viveiro com cobertura sombrite $50 \%$ e irrigação diária por microaspersão. Lotes de plantas ( $n=20$, por espécie com quatro repetições) foram submetidos a quatro tratamentos distintos. Lote A capacidade de campo/nutrido (CCN) adubado com NPK 4:20:20 em solução aquosa a $10 \%, 1 \mathrm{~mL}$ por tubete, duas vezes por semana nos primeiros dois meses de desenvolvimento e $30 \%$ a partir do segundo mês, e $1 \mathrm{~mL}$ por tubete de solução de micronutrientes (de acordo com especificações do fabricante), quinzenalmente. Lote B capacidade de campo/desnutrido (CCD), no qual as plantas foram mantidas em substrato drenado, mas sem nenhuma adubação ao longo do período experimental. Lote $\mathrm{C}$ - alagado/ nutrido (ALN), adubado ao longo do período experimental, nas mesmas dosagens que o lote $\mathrm{CCN}$, e mantido nas condições de alagamento sem aeração. $\mathrm{O}$ alagamento foi induzido, em plântulas com trinta dias a partir da emergência em lotes homogênios (Santiago \& Paoli 2003). Lote D alagado/desnutrido (ALD), no qual as plântulas não receberam adubação e foram mantidas em substrato alagado ao longo do período experimental de seis meses. Realizou-se o rodízio periódico das bandejas, alterando-se a posição das plântulas nas bancadas. Não foi efetuada aeração em nenhum tratamento alagado, para a indução da hipóxia.

O estudo morfo-anatômico foi realizado em plântulas com até uma semana após a exposição da raiz primária e 
plantas jovens a partir do terceiro mês de emergência. Elas foram colocadas em placas de Petri, forradas com papel de filtro mantido embebido em cerca de $1 \mathrm{~mL}$ de água destilada, e acondicionadas em Câmara de Germinação BOD a $25^{\circ} \mathrm{C}$ sob luz fluorescente branca contínua. A partir de material fresco ou fixado em FAA em etanol 50\% (Johansen 1940) foram realizadas secções transversais e longitudinais nas regiões basais do caule e raiz principal, à mão livre e com auxílio de micrótomo rotatório Reichert-Jung-2040. Foram confeccionadas lâminas provisórias montadas em água destilada e semipermanentes, em glicerina a $50 \%$ (Vasconcelos \& Coutinho 1960) coradas com solução alcóolica de safranina $1 \%$ e solução aquosa de azul de astra $1 \%$, e lâminas permanentes, em historresina JB4 Policrilato Glicol, coradas com azul de toluidina $0,05 \%$ montadas em Entelan (Gerrits 1991). As fotomicrografias foram obtidas em fotomicroscópio Olympus BX40, e fotomicroscópio Zeiss MC 80DX.

Os dados de biomassa vegetal foram obtidos pela análise da produção de matéria fresca e matéria seca em estufa de secagem a $105^{\circ} \mathrm{C}$, através de pesagens das amostras de raízes, da região do colo e sistema aéreo (Santiago \& Paoli 2003), em balança Micronal B600, ao final do período experimental de seis meses.

A análise estatística das variações das superfícies médias entre os tratamentos, para cada espécie, foi realizado aplicando-se o ANOVA, teste de Tukey sobre o logarítimo dos valores, com auxílio do programa Systat 9.0 para observações pareadas, com 5\% de significância (Santana \& Ranal 2004).

\section{Resultados}

Morfologia - a secção transversal do caule de plantas jovens de Guibourtia hymenifolia, com duas semanas de desenvolvimento, evidenciou uma epiderme simples com tricomas unicelulares, seguida de parênquima cortical e feixes vasculares distribuídos em torno de um parênquima medular. No início de crescimento secundário, bastante evidente a partir do terceiro mês de emergência, notou-se a atividade do felogênio e câmbio vascular que promoveram o colápso de células do parênquima cortical. O surgimento de novas células por uma ou mais divisões periclinais (aditivas), seguidas de divisões anticlinais (multiplicativas) que promovem o aumento em espessura do órgão, aumentam a pressão sobre as células do parênquima cortical, este evento é acompanhado de suberização das células colabadas e redução do parênquima cortical em relação à espessura do cilindro caulinar (figuras 1-3), não culminando no entanto, na formação de aerênquima em nenhum dos lotes testados. Nos lotes alagados (ALN e ALD), a ocorrência de lenticelas foi desprezível, quando presentes, no entanto, não apresentavam tecido frouxo associado (figura 4). $\mathrm{Na}$ raiz, em crescimento secundário, evidenciou-se uma periderme descontínua revestindo o córtex parenquimático e fibras esclerenquimáticas associadas ao floema secundário. O xilema apresentou vasos difusos, de tamanho relativamente uniforme, sendo perceptíveis os raios (figura 5). As secções das plantas jovens dos lotes alagados, independentemente do estado nutricional, não revelaram modificações morfológicas significativas em resposta ao estresse por alagamento, tanto no caule quanto na raiz. Quanto ao conteúdo de amido de reserva, verificou-se que, em geral, sua ocorrência nas células do parênquima foi menor tanto nos lotes desnutridos quanto nos lotes alagados, quando comparados aos lotes $\mathrm{CCN}$ (figuras 6-9).

Em Genipa americana, a secção transversal em plântula com duas semanas de desenvolvimento, evidenciou no caule a epiderme simples, com papilas, córtex com 12-15 camadas de parênquima e feixes vasculares em torno de um parênquima medular (figura 10), a raiz inicia cedo o crescimento secundário, sendo possível observar ainda uma epiderme simples, 10-11 camadas de parênquima cortical, endoderme e periciclo distintos (figura 11). Nesta espécie, alguns indivíduos do lote controle $(\mathrm{CCN})$ apresentaram raízes adventícias com aerênquima distinto, estas estruturas, no entanto, foram mais frequentes nas plantas submetidas ao alagamento ALN (figura 12). Nos lotes alagados, independentemente do estado nutricional, verificou-se tanto no caule quanto na raiz, o surgimento de aerênquima lisógeno (figuras 13-14), além da hipertrofia lenticelar (figura 15).

Biomassa - em Guibourtia hymenifolia, verificou-se que somente os valores médios de matéria fresca do módulo de expressão entre tratamento e controle, nos lotes desnutridos, não diferiram significativamente entre si. Para os demais parâmetros, nesta espécie, as médias de biomassa dos lotes em capacidade de campo foram superiores às dos lotes alagados, tanto para a matéria fresca quanto seca. Nesta espécie, verificouse ainda que tanto nos lotes controle quanto nos de tratamento, ocorreu distribuição maior de biomassa para o sistema aéreo. Já em relação à biomassa da raiz, esta foi significativamente maior nos lotes desnutridos mantidos em capacidade de campo (tabela 1).

Nas plantas jovens de G. americana, dos lotes desnutridos, os valores de biomassa fresca da parte aérea foram superiores nos lotes alagados, no entanto os valores de peso seco não diferem entre si. Também 

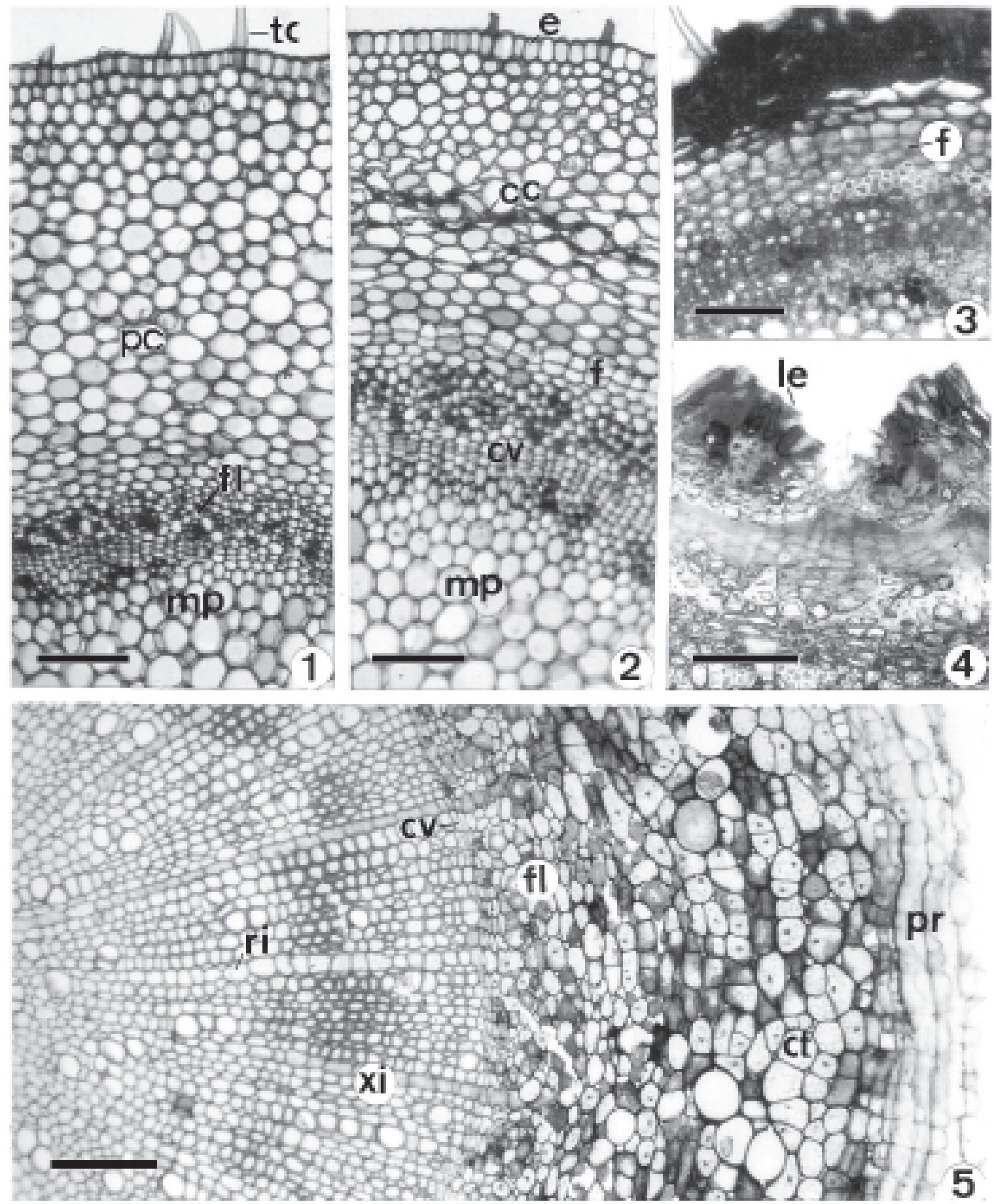

Figuras 1-5. Secção transversal em caule de plântulas e plantas jovens de Guibourtia hymenifolia (1, 2, 3 e $5=$ CCD) 2 . Caule em início de crescimento secundário. 3. Estádio posterior do crescimento secundário. 4. Detalhe de lenticela, lote ALD.

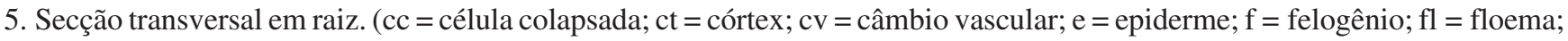
$\mathrm{le}=$ lenticela; $\mathrm{mp}=$ medula parenquimática; $\mathrm{pr}=$ periderme; $\mathrm{ri}=$ raio; $\mathrm{tc}=$ tricoma; $\mathrm{xi}=$ xilema). Barras $=10 \mu \mathrm{m}(1-5)$.

Figures 1-5. Transversal section of seedlings and younger plants stem of Guibourtia hymenifolia $(1,2,3$ and $5=\mathrm{CCD})$. Begining of secondary growing. 3. Posterior stadium of the secondary growing. 4. Detail of the lenticels, lot ALD. Transversal section of the root. $(\mathrm{cc}=$ compress cells; $\mathrm{ct}=$ cortical region; $\mathrm{cv}=$ vascular cambium; $\mathrm{e}=$ epidermis; $\mathrm{f}=$ phellogen; $\mathrm{fl}=$ phloem; $\mathrm{le}=$ lenticels; $\mathrm{mp}=$ parenchyma marrow; $\mathrm{pr}=$ periderm; $\mathrm{ri}=$ ray; $\mathrm{tc}=$ hair $; \mathrm{xi}=\mathrm{xylem})$. Bars $=10 \mu \mathrm{m}(1-5)$. 

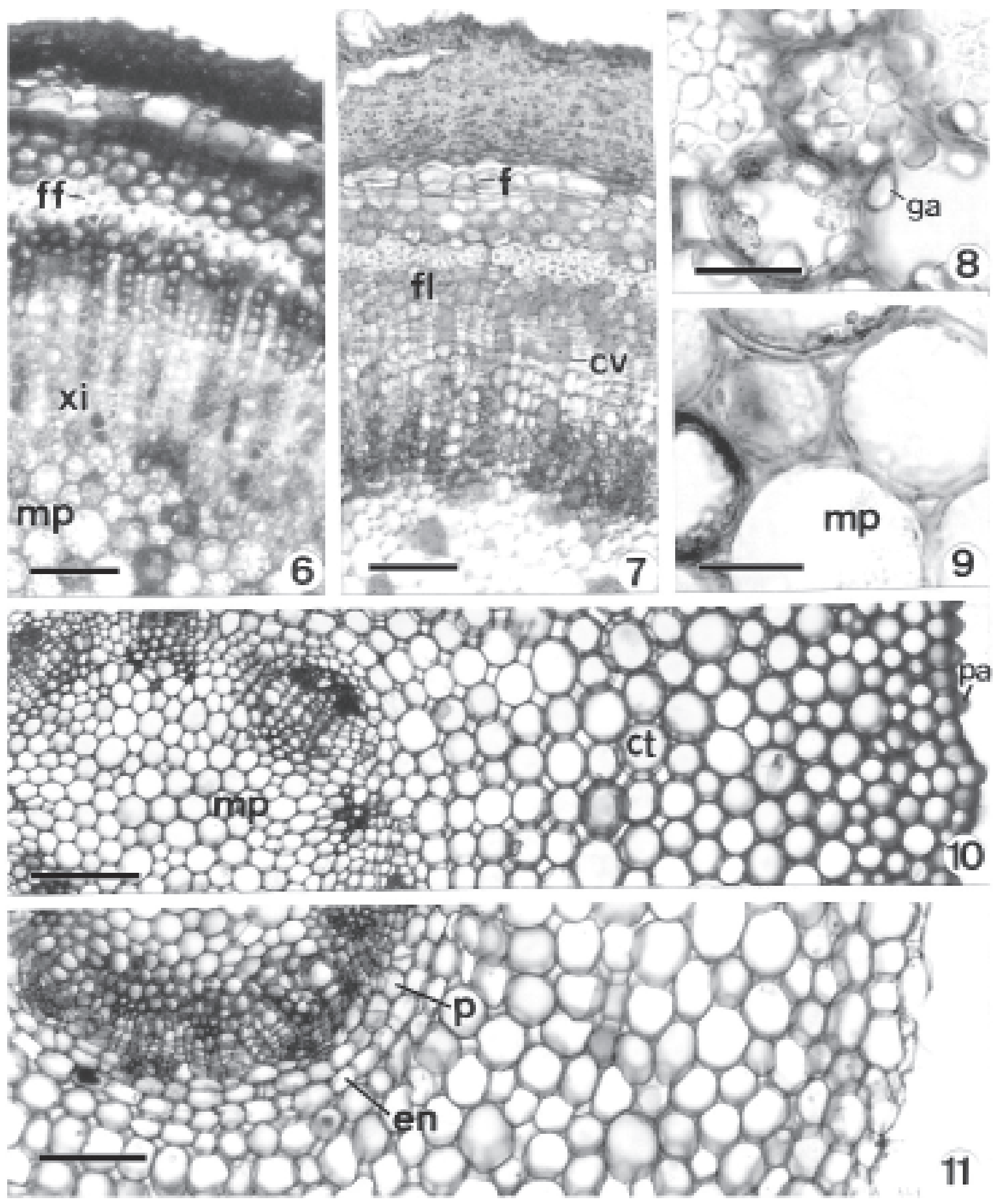

Figuras 6-11. Secção transversal em caule de plantas jovens de Guibourtia hymenifolia, lote CCN. 7. Secção transversal em caule, lote ALN. 8. Detalhe da medula parenquimática, lote CCN. 9 Detalhe da medula parenquimática, lote ALN. 10. Secção transversal em caule de plântulas e plantas jovens de Genipa americana L. 11. Secção transversal em raiz. (ct = córtex; $\mathrm{cv}=$ câmbio vascular; $\mathrm{en}=$ endoderme; $\mathrm{f}=$ felogênio; $\mathrm{ff}=$ feixe de fibras; $\mathrm{fl}=$ floema; $\mathrm{ga}=$ grão de amido; $\mathrm{mp}=$ medula parenquimática; $\mathrm{p}=$ periciclo; $\mathrm{pa}=$ papila; $\mathrm{xi}=$ xilema). Barras $=20 \mu \mathrm{m}(6-7), 2,5 \mu \mathrm{m}(8-9), 10 \mu \mathrm{m}(10-11)$.

Figures 6-11. Transversal section of the stem of young plants of Guibourtia hymenifolia, lot CCN. 7. Transversal section of the stem, lot ALN. 8. Detail of the parenchyma marrow, lot CCN. 9. Detail of the parenchyma marrow, lot ALN. 10. Transversal section of the stem of seedlings and young plants of Genipa americana. 11. Transversal section of the root. (ct $=$ cortical region; $\mathrm{cv}=$ vascular cambium; $\mathrm{en}=$ endoderm $; \mathrm{f}=$ fhellogen; $\mathrm{ff}=$ blunders fibers; $\mathrm{fl}=\mathrm{phloem} ; \mathrm{ga}=$ starch grain; $\mathrm{mp}=$ parenchyma marrow; $\mathrm{p}=$ pericycle; $\mathrm{pa}=$ papilla; $\mathrm{xi}=\mathrm{xylem})$. Bars $=20 \mu \mathrm{m}(6-7), 2,5 \mu \mathrm{m}(8-9), 10 \mu \mathrm{m}(10-11)$. 


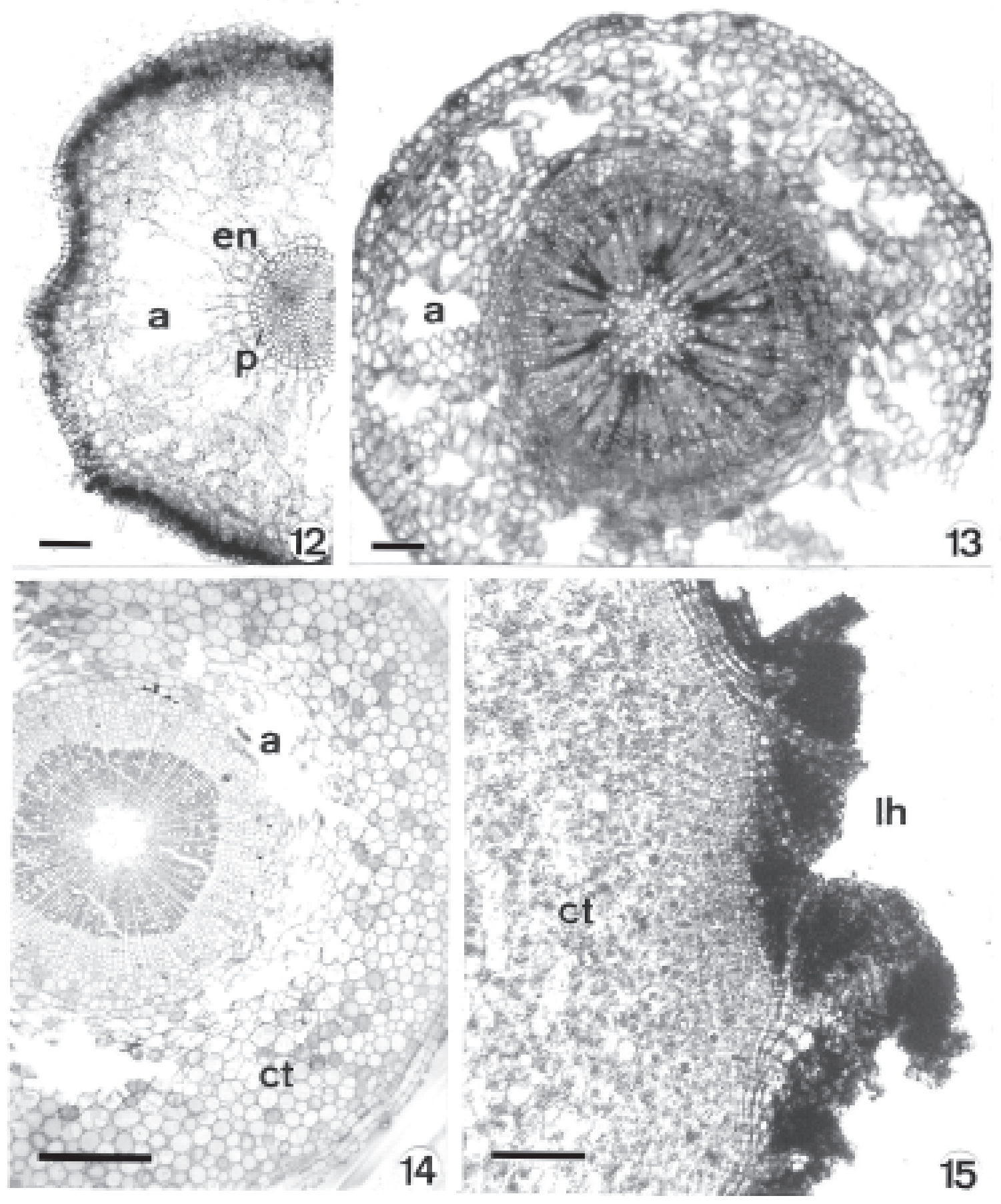

Figuras 12-15. Secção transversal da raiz adventícia em planta jovem de Genipa americana, lote CCN. 12. Raiz adventícia destacando o aerênquima lisógeno. 13. Secção transversal da raiz principal, lote ALN. 15. Secção transversal em caule, lote ALN. 16. Lenticela hipertrofiada em caule, lote ALN. ( $\mathrm{a}=$ aerênquima; $c t=$ córtex; en = endoderme; $\mathrm{lh}=$ lenticela hipertrofiada; $\mathrm{p}=$ periciclo). Barras $=20 \mu \mathrm{m}(12), 5 \mu \mathrm{m}(13), 20 \mu \mathrm{m}(14-15)$.

Figures 12-15. Transversal section of the adventitious root of the young plants of Genipa americana, lot CCN. 13. Schema of the adventitious root showing the lysogenic aerenchyma. 13. Transversal section of the principal root, lot ALN. 15. Transversal section of the stem, lot ALN. 16. Hypertrophic lenticels in stem, lot ALN. $(\mathrm{a}=$ aerenchyma; $\mathrm{ct}=$ cortical region; en = endoderm; $\mathrm{lh}=$ lenticels hypertrophy; $\mathrm{p}=$ pericycle). Bars $=20 \mu \mathrm{m}$ (12), $5 \mu \mathrm{m}(13), 20 \mu \mathrm{m}(14-15)$. 
não diferem os valores de biomassa seca da raiz entre tratamento e controle nos lotes desnutridos e o lote controle nutrido. Em geral, as médias de biomassa do sistema aéreo, raiz e módulo de expressão das plantas alagadas foram superiores àquelas verificadas nos lotes controle (tabela 1). Nos lotes nutridos as relações entre tratamento e controle foram semelhantes àquelas verificadas nos lotes desnutridos, ou seja, as médias verificadas nos lotes tratamento e controle diferiram estatisticamente em biomassa do sistema aéreo, módulo de expressão e matéria fresca do sistema radicial.

\section{Discussão}

A plasticidade das respostas morfo-anatômicas estiveram diretamente associadas ao alagamento do substrato, no entanto, o estado nutricional das plantas influenciou na freqüência e intensidade destas respostas. He et al. (1992) também verificaram a influência do estado nutricional sobre as respostas morfo-anatômicas em raízes de milho. Kolb et al. (1998) estudando as respostas de Sebastiania commersoniana (Baillon) Smith \& Downs, ao alagamento, verificaram maior conteúdo de amido nas células parenquimáticas corticais nas plantas controle em relação às plantas mantidas alagadas por 60 dias. Os autores sugerem que a maior demanda de carbono nas plantas alagadas pode estar relacionada às alterações morfo-anatômicas como lenticelas hipertróficas e novas raízes. Em $G$. hymenifolia mesmo não expressando modificações morfológicas, o alagamento pode ter promovido uma alta demanda de amido.

A formação de raízes adventícias citadas pela maioria dos autores (Hook 1984, Crawford 1992, Parolin 2001) está associada ao alagamento do substrato, ocorrendo nas porções submersas a partir do hipocótilo. Neste estudo, verificou-se que o fator nutricional influenciou a ocorrência dessas estruturas em G. americana. Estes resultados contrastam com os de Andrade et al. (1999) que não verificaram alterações morfológicas em plântulas alagadas nesta espécie. Medri et al. (1998) estudando plantas alagadas de P. dubium (Spreng.) Taub., não constataram a ocorrência de raízes adventícias, enquanto Santiago \& Paoli (2003) descreveram esta estrutura para esta espécie em condições semelhantes.

Comparando as médias de biomassa vegetal entre os tratamentos e entre as espécies para os lotes CCD e ALD, verificou-se que as plântulas de G. hymenifolia apresentaram, em geral, médias maiores em biomassa

Tabela 1. Valores médios de biomassa vegetal $(\mathrm{g})$ de plantas jovens submetidas a seis meses estresse por alagamento. $(\mathrm{PA}=$ parte aérea; $\mathrm{RA}$ = raiz; $\mathrm{ME}$ = módulo de expressão; $\mathrm{CCD}$ = capacidade de campo desnutrida; $\mathrm{ALD}=$ alagamento desnutrida; $\mathrm{CCN}=$ capacidade de campo nutrida; $\mathrm{ALN}=$ alagamento nutrida $\mathrm{C}=$ controle; $\mathrm{T}=$ tratamento). Valores seguidos de mesma letra em coluna, para cada bloco, não diferem significativamente entre si.

Table 1. Means values of vegetal biomass $(\mathrm{g})$ of young plants after six months flooded. $(\mathrm{PA}=$ aerial portion; RA = root; $\mathrm{ME}=$ expression module; $\mathrm{CCD}=$ nutrient poor, drained soil; $\mathrm{ALD}=$ nutrient poor, flooded soil; $\mathrm{CCN}=$ rich, drained soil; $\mathrm{ALN}=$ rich flooded soil; $\mathrm{C}=$ control; $\mathrm{T}=$ stressed). Values followed by the same letters, in columns, for every group, are not significantly different.

\begin{tabular}{|c|c|c|c|c|}
\hline \multirow[t]{2}{*}{ Lotes } & \multicolumn{2}{|c|}{ Guibourtia hymenifolia } & \multicolumn{2}{|c|}{ Genipa americana } \\
\hline & Peso fresco $(\mathrm{g})$ & Peso seco $(\mathrm{g})$ & Peso fresco $(\mathrm{g})$ & Peso seco $(\mathrm{g})$ \\
\hline $\mathrm{PA}-\mathrm{CCD}(\mathrm{C})$ & $1,08 \mathrm{a}$ & $0,64 \mathrm{a}$ & $0,50 \mathrm{a}$ & $0,22 \mathrm{a}$ \\
\hline PA-ALD(T) & $0,65 \mathrm{~b}$ & $0,39 \mathrm{~b}$ & $1,90 \mathrm{~b}$ & $0,44 \mathrm{a}$ \\
\hline $\mathrm{PA}-\mathrm{CCN}(\mathrm{C})$ & $1,91 \mathrm{c}$ & $0,83 \mathrm{c}$ & $3,81 \mathrm{~b}$ & $1,28 \mathrm{~b}$ \\
\hline PA-ALN(T) & $0,28 \mathrm{~d}$ & $0,18 \mathrm{~d}$ & $5,65 \mathrm{c}$ & $2,22 \mathrm{c}$ \\
\hline $\mathrm{RA}-\mathrm{CCD}(\mathrm{C})$ & $0,81 \mathrm{a}$ & $0,33 \mathrm{a}$ & $0,98 \mathrm{a}$ & $0,35 \mathrm{a}$ \\
\hline RA-ALD(T) & $0,30 \mathrm{~b}$ & $0,15 \mathrm{~b}$ & $1,09 \mathrm{~b}$ & $0,37 \mathrm{a}$ \\
\hline $\mathrm{RA}-\mathrm{CCN}(\mathrm{C})$ & $0,48 c$ & $0,28 \mathrm{c}$ & $3,49 c$ & $1,13 \mathrm{a}$ \\
\hline RA-ALN(T) & $0,06 \mathrm{~d}$ & $0,02 \mathrm{~d}$ & $5,11 \mathrm{~d}$ & $1,38 \mathrm{~b}$ \\
\hline $\mathrm{ME}-\mathrm{CCD}(\mathrm{C})$ & $0,35 \mathrm{a}$ & $0,22 \mathrm{a}$ & $0,40 \mathrm{a}$ & $0,18 \mathrm{a}$ \\
\hline ME - ALD(T) & $0,35 \mathrm{a}$ & $0,16 \mathrm{~b}$ & $0,95 \mathrm{~b}$ & $0,41 \mathrm{~b}$ \\
\hline $\mathrm{ME}-\mathrm{CCN}(\mathrm{C})$ & $0,23 \mathrm{~b}$ & $0,10 \mathrm{c}$ & $0,53 \mathrm{a}$ & $0,22 \mathrm{a}$ \\
\hline ME - ALN(T) & $0,03 \mathrm{c}$ & $0,01 \mathrm{~d}$ & $1,46 c$ & $1,39 \mathrm{c}$ \\
\hline
\end{tabular}


do sistema aéreo, do que do sistema radicial, tanto nos lotes controle quanto tratamento (tabela 1), comparando os lotes tratamento e controle, observou-se também a redução da matéria seca da raiz. De maneira diferente, em $G$. americana, verificou-se um alto investimento em biomassa para o desenvolvimento do sistema radicial, sendo que nos lotes desnutridos, o tratamento apresentou maior peso de matéria fresca da raiz quando comparado com o controle.

A redução da matéria seca da raiz em função do alagamento é descrita em muitas espécies (Kozlowski 1984, Medri et al. 1998, Andrade et al. 1999), mesmo com o surgimento de raízes adventícias, observa-se o decréscimo da biomassa do sistema radicial uma vez que o alagamento provoca a morte de muitas raízes. A contribuição em biomassa das raízes adventícias é relativamente pequena devido ao aerênquima e espaços intercelulares.

O alagamento promove em geral redução nos níveis de NPK nos tecidos (Kozlowski 1984, Serôdio \& Novais 1991), a morte de raízes em alagamento são conferidas ao acúmulo de etileno e outros compostos tóxicos (Jackson \& Drew 1984, Lobo \& Joly, 2000). Em geral a redução da matéria seca da raiz foi maior nos lotes desnutridos sugerindo que em plantas bem nutridas os efeitos destrutivos e inibitórios do etileno possivelmente devam ser menores.

Mielke et al. (2005) estudando Annona glabra L., uma espécie descrita pelos autores como altamente tolerante ao alagamento, verificaram que num período de 56 dias, o alagamento promoveu aumentos significativos na biomassa das raízes, caules e planta inteira, sem induzir sintomas de estresse.

$\mathrm{O}$ aumento em biomassa verificado em G. americana nos lotes desnutridos, a boa performance para este parâmetro nos lotes nutridos, bem como as modificações morfológicas são contrastantes com os dados obtidos por Andrade et al. (1999) que verificaram em geral redução de biomassa e ausência de caracteres morfológicos e Mielke et al. (2003) que também verificaram redução na biomassa das raízes e redução do crescimento em G. americana mantida em alagamento do substrato, embora, segundo os autores, o tratamento não tenha afetado a taxa de sobrevivência das plantas. Estes resultados refletem variadas respostas das plantas ao alagamento, que podem estar associadas às condições nutricionais, efeitos sinérgicos entre $o$ tratamento e fatores ambientais como luz e temperatura, a intensidade, o tempo de duração do estresse, ou mesmo o potencial genético do lote testado, sugerindo cuidado nas interpretações de respostas ao alagamento ao nível de espécie.

Neste estudo, o melhor desempenho em condições de alagamento por um período de seis meses, foi de Genipa americana, que apresentou as mais efetivas modificações morfológicas como a hipertrofia lenticelar, a expressão de raízes adventícias e a formação de aerênquima lisígeno, bem como maior ganho em biomassa da parte aérea e sistema radicial, o que reflete uma alta plasticidade corroborando com a larga ocorrência de populações dessa espécie em áreas sujeitas a alagamentos periódicos como por exemplo, no Pantanal do Miranda, MS.

Embora o valor adaptativo de expressões morfológicas em resposta ao estresse seja amplamente discutido, destaca-se que a adaptação no contexto biológico se processa ao longo do tempo, sob a luz da seleção natural, envolvendo a seleção de complexos de genes coadaptados (Freeman et al. 1993) sendo, portanto, própria à espécie ou mesmo às populações.

A adaptação não pode ser confundida com a mera expressão de caracteres em resposta às pressões ambientais. Larcher (2000) aponta que dependendo do potencial de resposta, da intensidade e tempo de duração do estresse, o organismo pode atravessar um período de restituição caracterizado por processos de reparo pela síntese protéica ou síntese "de novo" de substâncias de proteção, devido à melhora na estabilidade, a normalização pode acontecer mesmo sob estresse contínuo.

A adaptação é processual, e como tal, não se encerra no indivíduo, este pode ou não apenas expressar caracteres morfológicos ou fisiológicos ou ambos, através da ativação ou repressão gênica, e estes caracteres possuírem ou não um componente adaptativo. Assim, o indivíduo não se adapta, mas se normaliza ou não, frente às pressões ambientais, podendo contribuir ou não com caracteres de valor adaptativo ao longo do tempo.

É importante destacar que as grandes variações nos aspectos morfológicos em resposta ao alagamento não permite uma determinação de tolerância baseada somente nestas características, uma vez que, neste estudo ocorreram indivíduos que aparentemente não expressaram nenhuma modificação morfológica dentro de um mesmo lote tratamento. Essas variações, comuns em populações naturais, sugerem um complexo de caracteres adaptativos não só estruturais como também fisiológicos. 


\section{Referências bibliográficas}

ANDRADE, A.C.S., RAMOS, F.N., SOUZA, A.F., LOUREIRO, M.B. \& BASTOS, R. 1999. Flooding effects in seedlings of Cytharexillum myrianthum Cham. and Genipa americana L.: responses of two neotropical lowland tree species. Revista Brasileira de Botânica 22:281-285.

CRAWFORD, R.M.M. 1992. Oxygen availability as an ecological limit to plant distribution. Advances in Ecological Research 23:93-185.

CUTTER, E.G. 1978. Plant anatomy. Part 1: cells and tissues. Edward Arnold, England.

DANTAS, B.F., ARAGÃO, C.A. \& ALVES, J.D. 2001. Cálcio e o desenvolvimento de aerênquimas e atividade da celulase em plântulas de milho submetidas a hipóxia. Scientia Agricola 58:251-257.

DREW, M.C., JACKSON, M.B, JIFFARD, S.C. \& CAMPBEL, R. 1981. Inhibition by silver ions of gas space (aerenchyma) formation in adventitious roots of Zea mays L. subjected to exogenous ethylene or to oxygen deficiency. Planta 153:217-224.

GERRITS, P.O. 1991. The application of glycol methacrylate in histotechnology, some fundamental principles. State University Groningen, Groningen.

FREEMAN, D.C., GRAHAM, J.H. \& EMLEN, J.M. 1993. Developmental stability in plants: Symmetries, stress and epigenesis. Genetica 89:97-119.

HE, C., MORGAN, W. \& DREW, M.C. 1992. Enhanced sensitivity to ethylene in nitrogen or phosphate starved roots of Zea mays L. during aerenchyma formation. Plant Physiology 98:137-142.

HE, C., FINLAYSON, S.A., DREW, M.C., JORDAN, W.R. \& MOTGAN, P.W. 1996. Ethylene biosynthesis during aerenchyma formation in roots of maize subjected to mechanical impedance and hypoxia. Plant Physiology 112:1679-1685.

HE, J.B., BOGEMANN, G.M., STEEG, H.M., RIJNDERS, J.G.H.M., VOESENEK, L.A.C.J. \& BLOM, C.W.P.M. 1999. Survival tactics of Ranunculus species in river floodplains. Oecologia 118:1-8.

HOOK, D. 1984. Adaptations to flooding with fresh water. In Flooding and Plant Growth. (T.T. Kozlowski, ed.). Academic Press, San Diego, p.265-294.

JACKSON, M.B. \& DREW, M.C. 1984. Effects of flooding on growth and metabolism of herbaceous plants. In Flooding and Plant Growth. (T.T. Kozlowski, ed.). Academic Press, San Diego, p.47-127.

JANIESCH, P. 1991. Ecophysiological adaptations of higher plants in natural communities to waterlogging. In Ecological responses to environmental stresses. (J. Rozema \& J.A.C. Verkleij, eds.). Kluwer Academic Publishers, Dardrecht, p.50-60.

JOHANSEN, D.A. 1940. Plant microtechnique. McGraw-Hill, New York.
JOLY, C.A. 1996. The role of oxygen diffusion to the root system on flooding tolerance of tropical trees. Revista Brasileira de Biologia 56:375-382.

KOLB, R.M., MEDRI, M.E, BIANCHINI, E., PIMENTA, J.A., GILONI, P.C. \& CORREA, GT. 1998. Anatomia ecológica de Sebastiania commersoniana (Baillon) Smith \& Downs (Euphorbiaceae) submetida ao alagamento. Revista Brasileira de Botânica 21:305-312.

KOZLOWSKI, T.T. 1984. Responses of woody plants to flooding. In Flooding and plant growth. (T.T. Kozlowski, ed.). Academic Press, San Diego, p.129-163.

LARCHER, W. 2000. Ecofisiologia vegetal. RiMa, São Carlos.

LENSSEN, J.P.M., KLEUNEN, M., FISHER, M. \& KROON, H. 2004. Local adaptation of the clonal plant Ranunculus reptans to flooding along a small-scale gradient. Journal of Ecology. 92:696-706.

LOBO, P.C. \& JOLY, C.A. 1995. Mecanismos de tolerância à inundação de plantas de Talauma ovata St. Hil. (Magnoliaceae), uma espécie típica de mata de brejo. Revista Brasileira de Botânica 18:177-183.

LOBO, P.C. \& JOLY, C.A. 2000. Aspectos ecofisiológicos da vegetação de mata ciliar do sudeste do Brasil. In Matas Ciliares: Conservação e recuperação. (R.R. Rodrigues \& H.F. Leitão Filho, eds.). Edusp/Fapesp, São Paulo, p.143157.

MEDRI, M.E., BIANCHINI, E., PIMENTA, J.A., DELGADO, M.F. \& CORREA, G.T. 1998. Aspectos morfo-anatômicos e fisiológicos de Peltophorum dubium (Spr.) Taub. submetida ao alagamento e à aplicação de etrel. Revista Brasileira de Botânica 21:261-267.

MIELKE, M.S., ALMEIDA, A-A.F., GOMES, F.P., AGUILAR, M.A.G. \& MANGABEIRA, P.A.O. 2003. Leaf gas exchange, chlorophyll fluorescence and growth responses of Genipa americana seedlings to soil flooding. Environmental and Experimental Botany 50:221-231.

MIELKE, M.S., MATOS, E.M., COUTO, V.B., ALMEIDA, A.-A.F., GOMES, F.P. \& MANGABEIRA, P.A.O. 2005. Some photosynthetic and growth responses of Annona glabra L. seedlings to soil flooding. Acta Botanica Brasilica 19:905-911.

PAROLIN, P. 2001. Senna reticulata, a pioner tree from amazonian várzea floodplains. The Botanical Review 67:239-254.

REID, D.M. \& BRADFORD, K.J. 1984. Effects of flooding on hormone relations. In Flooding and Plant Growth. (T.T. Kozlowski, ed.). Academic Press, San Diego, p.195-212.

SANTANA, D.G. \& RANAL, M.A. 2004. Análise da germinação: um enfoque estatístico. Editora UNB, Brasília.

SANTIAGO, E.F. \& PAOLI. A.A.S. 2003. O aumento em superfície em Adelia membranifolia (Müll. Arg.) Pax \& K. Hoffm. e Peltophorum dubium (Spreng.) Taub., em resposta ao estresse por deficiência nutricional e alagamento do substrato. Revista Brasileira de Botânica 26:503-513. 
SCATENA, V.L. \& MENEZES, N.L. 1996. Anatomia de raízes de Syngonanthus Ruhl. (Eriocaulaceae). Revista Brasileira de Biologia 56:333-343.

SERÔDIO, M.I. \& NOVAIS, M.C. 1991. Nutrientes, fotossíntese e crescimento de trigo em condições de alagamento do solo. Revista Brasileira de Botânica 14:97-101.

VARTAPETIAN, B.B. \& JACKSON, M.B. 1997. Plant adaptation to anaerobic stress. Annals of Botany (Supplement A) 79:3-20.
VASCONCELOS, J.C. \& COUTINHO, M.C.P. 1960. Noções sobre anatomia das plantas superiores. Serviço de Informações Agrícolas, Lisboa.

WAMPLE, R.L. \& REID, D.M. 1979. The role of endogenous auxins and ethylene in the formation of adventitious roots and hypocotyl hypertrophy in flooded sunflower plants (Helianthus annus L.). Plant Physiology 45:219-226. 